\title{
MERCANTILIZAÇÃO DAS PRÁTICAS CORPORAIS: O ESPORTE NA SOCIEDADE DE CONSUMO DE MASSA
}

\author{
MARKETING OF CORPORAL PRACTICES: \\ THE SPORT IN THE SOCIETY OF MASS CONSUMPTION
}

\author{
Geraldo Di Giovanni ${ }^{1}$ \\ ${ }^{1}$ Nepp; Unicamp
}

Recebido para publicação em: 05/10/2004

Aceito para publicação em: 17/02/2005

\begin{abstract}
RESUMO
O objeto deste trabalho é a discussão das relações entre esporte e consumo na sociedade moderna. Pretende-se demonstrar como os fenômenos relativos ao consumo ganham uma nova atualidade, numa perspectiva histórica, especialmente em razão de um novo e abrangente quadro de valores sociais. Mercantilização, individualização e surgimento de modelos são concietos que permitem captar a nova realidade do esporte no mundo contemporâneo e sua transformação em mercadoria.
\end{abstract}

Palavras-chave: Mercantilização, sociedade de consumo, esporte

\section{Introdução}

O propósito do presente artigo é procurar entender os fenômenos relativos às práticas corporais, em geral, e ao esporte, em particular, à luz das teorias relativas à expansão do consumo nas sociedades contemporâneas. Considerados como traços importantes da cultura contemporânea, parte-se da constatação que tais fenômenos têm sido submetidos a um intenso processo de mercantilização, o que significa - em termos mais simples - sua constituição em mercadorias, tal como ocorre com outros bens materiais e culturais nas sociedades capitalistas. A pergunta fundamental subjacente ao texto é, portanto: como e porque as práticas culturais e o esporte se mercantilizam? Ou seja: como adentram ao universo do consumo, constituindo um setor de produção de bens e serviços, bem como um importante campo de consumo?

Como se trata de um estudo exploratório, ${ }^{1}$ do qual se pretende extrair uma linha de futuras pesquisas, as quais poderiam ser caracterizadas como uma "economia do esporte", o presente texto tem a pretensão de estabelecer algumas diretrizes metodológicas, sem que se excluam outras

\footnotetext{
${ }^{1}$ Estamos apoiados na obra de Jean Baudrillard, especialmente os textos relativos a sua interpretação da sociedade de consumo. Também nos baseamos na Primeira Parte do livro A Questão dos Remédios no Brasil - produção e consumo, de Geraldo Di Giovanni.
} 
possibilidades de abordagens que serão enunciadas oportunamente. Convém frisar que a abordagem do tema a partir da perspectiva do consumo é apenas uma dentre outras possíveis. Sua escolha baseia-se no fato de que a constituição histórica de um "ramo" da economia (especialmente quando estão envolvidos bens culturais - e este parece ser o caso dos esportes) depende do surgimento de uma constelação de fatores, que vão desde a constituição de uma economia capitalista, pensada na plenitude do termo, até a existência de um background sócio-cultural que denominaremos genericamente de sociedade de consumo de massa, bem como, de acordo com o capítulo precedente, da existência de um estoque social de tempo disponível.

Cabe, portanto, uma incursão interpretativa sobre tal substrato, no sentido de descrever alguns traços que, em nosso modo de entender, possibilitam a constituição de bens culturais em mercadorias.

Deste ponto de vista, a perspectiva metodológica deve ser aquela na qual os elementos quantitativos da análise econômica, tais como a expansão do mercado e o crescimento das unidades de produção e distribuição, por exemplo, ganham sua explicação a partir das transformações sociais e culturais que embasam os processos de consumo. Certamente, esta perspectiva histórica não é excludente; ao contrário, é complementar à análise econômica quantitativa.

Nos últimos decênios, nas sociedades modernas, tem ocorrido um intenso processo de associação entre o esporte e a atividade econômica. Não se trata apenas do aporte de um crescente volume de investimentos na atividade esportiva, tal como a constituição de clubes-empresas, patrocínios milionários para algumas modalidades esportivas, programação de espetáculos esportivos e outras atividades similares. Além da transformação do esporte em espetáculo de massa, visualizado como campo de investimento econômico, o esporte, pensado como atividade física, em sentido lato, tem invadido a vida do homem comum, proporcionando-lhe novas pautas de conduta nas quais o corpo tem um lugar central, na medida em que está associado a valores emergentes tais como "o natural", a saúde, a beleza física, o desempenho e, fundamentalmente, um certo tipo de competição que não é tipicamente "esportiva", mas que se infiltra em praticamente todos os campos da atividade coletiva.

Este artigo tem a intenção de relacionar os valores que acima foram apenas enunciados com a mercantilização das práticas corporais, seja como espetáculo esportivo, seja como um conjunto de práticas corporais que são valorizadas e às quais estão associadas "necessidades", "razões práticas" de origem muito diversa: reais ou imaginárias.

\section{Individualização, mercantilização e personalização}


Um dos traços mais marcantes das sociedades contemporâneas é a individualização do agentes sociais. Se isto de certa forma foi uma resposta às relações de produção típicas de uma economia capitalista, num sentido econômico, tem como resultado consolidar um tipo de sociabilidade que é absolutamente impessoal. Nas sociedades complexas, no modo de vida urbanoindustrial, pela sua própria densidade, as relações sociais não se dão de pessoa a pessoa, mas de papel social para papel social, gerando, em certa medida, uma compatibilidade lógica entre os requisitos de ordem produtiva e as características de ordem social. Estas duas marcas da moderna sociedade capitalista, da ordem urbano-industrial - individualização e despersonalização - são extremamente importantes para o raciocínio que retomaremos mais adiante.

Outro traço marcante das sociedades atuais é o seu caráter essencialmente competitivo, caráter este que se manifesta com maior ênfase no plano das economias capitalistas, sob a forma de concorrência entre os produtores de bens e serviços.

O processo de mercantilização, por outro lado, reflete a complexidade da divisão social de trabalho na sociedade urbano-industrial, bem como os princípios de organização da economia capitalista, na qual a atuação das "leis de bronze" que regem a concorrência entre os produtores faz com que passe a ocorrer a "produção pela produção", o produtivismo que faz aumentar a massa de mercadorias aportada ao mercado, bem como o surgimento de novos bens materiais ou culturais mercantilizados e a constituição sempre renovada de novos mercados.

\begin{abstract}
“(...) enquanto a ampliação da produção é uma lei de bronze do modo de produção capitalista, conseqüência ao mesmo tempo que condição da busca insaciável do lucro máximo, a extensão da demanda solvente em geral e da demanda de produtos fabricados em particular não cai em absoluto sob o âmbito desta lei. Pelo contrário, a extensão da demanda solvente é o problema que o capitalista está constantemente obrigado a resolver para poder realizar a ampliação da produção. É esta contradição, lei essencial da acumulação capitalista, entre a capacidade - ilimitada - de produzir e a - limitada - de consumir que, em definitivo, empurra o capitalismo a ampliar seus mercados e, em conseqüência, a criar constantemente novas necessidades de consumo “. ${ }^{2}$
\end{abstract}

O processo de mercantilização chega mesmo a atingir dimensões insólitas e surpreendentes, tão bem exemplificadas nas novas formas de comercialização do "verde", do "natural", atributos de um ambiente intencionalmente depredado e degradado que se recupera, agora, como privilégio. Deste modo, sempre novas áreas da atividade econômica passam a ser objeto de uma produção ou comercialização integradas e implantadas sob uma forma capitalista, constituindo assim também o seu mercado.

Numa sociedade desta natureza - individualizada, despersonalizada, mercantilizada e, sobretudo, competitiva - quais seriam os valores que orientam as relações sociais e tipificam sua sociabilidade? 


\section{Valores sociais e consumo}

A possibilidade que se tem de captar a existência de valores vem do fato de que, de uma forma ou de outra, todos os valores sociais encontram uma forma de materialização. Seja um símbolo gráfico ou sonoro, um objeto qualquer usado de um modo determinado, uma roupa, um gesto, uma prática corporal, qualquer coisa pode se tornar uma expressão de valores. Estes elementos materializados simbolizam, de um modo geral, e sinalizam para os membros da sociedade que seu portador, possuidor ou agente realiza uma forma qualquer de adesão valorativa.

É claro que, numa sociedade complexa, o quadro de valores também o é. Numa sociedade dividida em classes, gêneros, religiões, gerações, grupos políticos, etc., é praticamente impossível encontrar o princípio estruturador de todos estes valores, uma vez que este universo poderia ser comparado, dadas sua dinâmica e extensão, a um caleidoscópio, com movimentos aleatórios e imprevisíveis. Mas isto não é inteiramente verdade. Se o princípio estruturador das formas caleidoscópicas é a gravidade, parece ser possível, analogamente, pensar num princípio que estrutura pelo menos alguns valores vigentes nas sociedades contemporâneas. Qual seria o princípio desta estruturação?

A resposta exige que se estabeleçam alguns pressupostos. Em primeiro lugar, embora esteja claro que não existem valores perenes, é preciso esclarecer que existem valores mais duradouros que outros. Tudo indica que os valores mais perenes são aqueles correlatos às relações sociais que estruturam uma sociedade. Numa sociedade altamente dinâmica - como a nossa - é visível a mutabilidade dos quadros valorativos. Entretanto, é preciso frisar, em segundo lugar, que existem também valores mais coletivizados, que não estão restritos apenas a grupos ou segmentos particulares, mas que têm o atributo de atravessar algumas clivagens sociais, tais como classe, sexo, religião, etc. Em outras palavras, têm o atributo de serem inclusivos, abrangendo e incorporando os demais e que, acima de tudo, pelas condições sociais em que são produzidos ou utilizados, têm uma grande probabilidade de generalização. Isto posto, cremos poder afirmar que nas sociedades capitalistas contemporâneas, incluindo a sociedade brasileira, o campo de atividade social em que se localizam os valores mais coletivizados (e mais coletivizáveis), abrangentes e inclusivos, é o campo do consumo.

\section{Produtivismo e consumo}

${ }^{2}$ Granou, A. Consumo y Producción en el Sistema Capitalista, 1972, p. 5, grifo nosso. 
Como vimos, o produtivismo inerente à economia capitalista deriva de leis que constrangem os produtores individuais (as empresas) a aumentarem sua produtividade e, conseqüentemente, a massa de produtos ofertados. Seja nos mercados mais competitivos ou mais monopolizados, a busca da produtividade é uma constante no comportamento empresarial. Tal procedimento, generalizado no conjunto da economia, faz com que se desenvolva para todo o sistema uma capacidade teoricamente ilimitada de produção, que se contradiz com a capacidade limitada de consumo da sociedade capitalista. Em outros termos, realizar o valor da produção, fazer com que os bens e serviços produzidos sejam consumidos, é uma preocupação recorrente dos produtores. Tal "problema" tem sido resolvido historicamente de duas maneiras que não são excludentes. De um lado, procura-se ampliar a extensão dos mercados. De outros, procura-se gerar novos conjuntos de necessidades, face às inovações, dando origem a um infindável processo de produção de necessidades, processo este que escapa a mecanismos puramente econômicos, adentrando ao campo cultural, psicossocial e mesmo ideológico. É exatamente no bojo da contradição acima referida que se combinam a reprodução econômica, as condutas sociais e os valores.

\section{Individualismo, personalização e competição}

Individualismo e personalização são faces de uma mesma moeda. O primeiro aparece como contrapartida subjetiva de uma sociedade em que o indivíduo alcançou sua primazia: no mercado de trabalho, nos canais institucionalizados de mobilidade social. O individualismo tem sua medida social na idéia da performance, do desempenho, que não é apenas exigido de todos, mas também é almejado por todos. E é através do desempenho, real ou ostentado, que se realiza a personalização, o reconhecimento social. O individualismo se reflete nos comportamentos, a personalização se materializa nos símbolos. Ambos são lógica e sociologicamente compatíveis com o funcionamento dos mercados capitalistas.

Seja um símbolo gráfico, sonoro, um forma de conduta, um carro, um gesto, uma roupa, um objeto usado de modo determinado, qualquer coisa pode se tornar uma expressão de valores sociais. Portanto, a profusão de mercadorias advinda do caráter produtivista das economias capitalistas contemporâneas ganha um sentido próprio e uma nova função na sociedade impessoal (despersonalizada), individualista e competitiva: os objetos servem de meios de sinalização social; atuam como uma outra linguagem em que os objetos e comportamentos "falam" sobre seus portadores: são pobres ou ricos, marginais ou integrados, jovens ou velhos, da elite ou da massa. A partir dos objetos materiais ou culturais de que são portadores ou usuários, os homens se localizam 
reciprocamente nas hierarquias sociais e se auto-descrevem para os demais: o carro, a casa, a roupa, a caneta, o espetáculo teatral, o corpo, são muito mais que objetos de consumo. São o testemunho do sucesso ou do fracasso de seus portadores, são símbolos materializados dos valores que a sociedade de consumo instaura, reinstaura, cria e recria.

E é através desta permuta simbólica que os homens e os grupos sociais criam suas identidades num meio social cada vez mais denso e opaco. Não se tratam, pois, de táticas ocasionais de inserção e identificação social, mas "de uma instituição social que determina os comportamentos antes mesmo de ser refletida pela consciência dos atores sociais". 3

\section{Personalização: ideologia e tática social}

Se na multidão você vai sumindo vai se confundindo, pense bem.

A culpa é só sua, de mais ninguém.

Prá você não ser mais um, não virar lugar-comum, use Jeans Machine...

(Jingle dos anos 70)

Como vimos, as sociedades complexas são altamente impessoais. As relações sociais não se dão de "pessoa a pessoa", mas através de papéis sociais institucionalizados, de comportamentos socialmente prescritos nos quais a margem de subjetividade é fortemente estreitada. Também, a densidade social é grande. O volume de relações sociais é aumentado, a velocidade destas relações é acelerada, fazendo com que o reconhecimento social se faça através de símbolos e signos.

A mobilidade social individual, especialmente a ascensão social, depende, pois, da capacidade individual de manipulação deste universo simbólico, bem como de suas oportunidades econômicas, uma vez que o processo de mercantilização faz com que a grande maioria de bens culturais e materiais, dotados destas funções de signos, sejam distribuídos a partir de uma lógica de mercado. Além do mais, o caráter essencialmente competitivo das sociedades contemporâneas faz com que o posicionamento individual nas hierarquias sociais dependa, acima de tudo, da possibilidade (econômica) e da capacidade (cultural) de dispor e "jogar" com os signos.

O processo de personalização passa, desta forma, por este circuito: os indivíduos competem no sentido de encontrarem reconhecimento social enquanto "pessoas", singularizadas por seus atributos materiais, sociais e culturais, numa sociedade que a priori não os reconhece como tal. 
O reconhecimento depende, pois, da performance, dentro de certas regras sociais que estabelecem nas palavras de Baudrillard - um fluxo e refluxo de signos pelos quais os indivíduos buscam tornarem-se "pessoas".

Se considerarmos as hierarquias sociais e econômicas vigentes na sociedade capitalista contemporânea, podemos perceber com facilidade que o acesso aos bens que efetivamente personalizam os indivíduos é restrito. Desta forma, os processos de personalização são, na verdade, processos competitivos entre indivíduos, entre grupos e mesmo no interior de grupos sociais. Talvez o exemplo clássico desta tendência sejam os processos de seleção de trabalhadores e empregados (principalmente de camadas médias), nos quais já se parte de um patamar de exigências que incluem desde uma formação técnica, uma formação cultural, e logicamente, uma boa aparência, expressão que designa a ostentação de um conjunto de atributos que devem satisfazer a um modelo de consumo individual: roupa, corte de cabelos e, muitas vezes, raça. Há, portanto, nestes modelos um conteúdo discriminatório que é liminar em todos os sentidos.

Não se trata somente da posse de objetos (e serviços) funcionais para seu possuidor; não se tratam apenas de objetos e serviços que discriminam positivamente seus possuidores, denotandolhes o prestígio individual ou de grupo. Trata-se também de uma linguagem, de um sistema de classificação das coisas e de seus detentores. Além do valor-de-uso que reflete uma funcionalidade prática; além do valor-de-troca que reflete um complexo intercâmbio econômico, os objetos são veículos materiais de uma linguagem que contém discriminantes sociais (positivos ou negativos) segundo determinados modelos, produzidos industrialmente pelos mass media. ${ }^{4}$

\section{Modelos: referências para o consumo e a hierarquização social}

A moda, como fenômeno sociológico, encarna perfeitamente a idéia de modelo, seja naquilo que tem de paradigmático, seja naquilo que tem de volátil. Reflete e se entrosa com a lógica do produtivismo, criando e alimentando um infinito processo de produção de necessidades. O "bom carro", por exemplo, deixa de ser definido pelo seu valor de uso, pela sua durabilidade, funcionalidade. Passa a ser o "carro do ano", definido muito mais - ano a ano - pelas suas metamorfoses aparentes que pelos seus elementos estruturais. O modelo, desta forma, não existe objetivamente. É uma construção baseada em quem usa, quem deve usá-lo e na quantidade efêmera de significações para as quais serve de suporte.

Entretanto, ao lado do modelo convive a série, a profusão de objetos industriais (e serviços), reais, que se diferenciam conforme são diferentes os seus portadores. Assim sendo, os

\footnotetext{
${ }^{3}$ Baudrillard, J. A moral dos objetos. Função-signo e lógica de classe, 1972, p.45.
} 
modelos, que na verdade são padrões ideais, são transferidos de cima para baixo nas hierarquias sociais, em rítmos retardados progressivamente. Em outras palavras, quando o acesso aos objetos e serviços de consumo é aberto aos estratos inferiores, já ocorre um déficit técnico, estético, temporal ou de "atualidade", que passa a servir de critério de discriminação. Entretanto, a cabal demonstração da instabilidade dos modelos (funcional às exigências da ordem produtiva) está na sua "infidelidade" a quaisquer princípios éticos, estéticos ou temporais. O brega se transforma em chique, o antigo em novo, o clássico em moderno, etc. E vice-versa. A fidelidade dos modelos se restringe à lógica dos discriminantes sociais.

\section{Esporte e consumo}

Se estas considerações são verdadeiras para os fenômenos do consumo em geral, cabe agora indagar como as atividades esportivas adentram este universo e quais são as especificidades que revelam enquanto bens e serviços mercantilizados nas sociedades contemporâneas.

Seja na forma de espetáculo esportivo, seja como práticas corporais individualizadas, é inegável o fato de que, nas últimas duas décadas, o esporte (e a atividade física, de um modo geral) tem se consituído num vasto e sempre crescente campo de investimento econômico. Tal crescimento está, como não poderia deixar de ser, associado aos mass media e ao surgimento de uma imensa rede de produção industrial de equipamentos, artefatos, academias, eventos e megaeventos, que dão a medida da importância destes fenômenos, quando comparados com períodos anteriores.

Dentro das considerações exposta anteriormente, podemos afirmar que estas transformações são derivadas de uma nova forma de valorização social do esporte e das atividades corporais, que se associa à constituição de um novo mercado. Não que este mercado deixasse de existir anteriormente. Entretanto, tudo indica que estamos numa etapa qualitativa e quantitativamente diferenciada das anteriores: trata-se de uma etapa onde se instaura um novo tipo dentre outros - de utilização do tempo livre, ${ }^{5}$ mediatizada pelo mercado capitalista. Poderíamos dizer, com Baudrillard, que a relação dos homens com o tempo livre se fez no passado basicamente através de seu valor de uso, enquanto na sociedade capitalista contemporânea enfatiza-se o valor de troca deste mesmo tempo livre, agora mercantilizável. Basta dizer que os preços das emissões de rádio e de televisão nada têm a ver com as qualidades intrínsecas dos produtos anunciados ou dos programas transmitidos. Seu único critério é o tempo de transmissão combinado com a

\footnotetext{
${ }^{4}$ Ver Baudrillard, J. La Société de Consommation: ses mythes, ses structures, 1970, pp. 139-141.

${ }^{5}$ Ver GEBARA, A. O tempo na construção do objeto de estudo da história do esporte, do lazer e da educação física. In: ENCONTRO NACIONAL DE HISTÓRIA DO ESPORTE, DO LAZER E DA EDUCAÇÃO FÍSICA, 2., 1994, Ponta Grossa. Anais... Ponta Grossa, 1994.
} 
categorização de horários, mais ou menos "nobres", que nada mais significam do que uma forma de apropriação de parte do estoque social de tempo disponível num determinado momento. Isto nos sugere como o tempo disponível torna-se mercadoria no processo de troca, principalmente na mercantilização dos bens culturais.

A hipótese que levantamos a respeito destas novas formas de valorização social do esporte e das práticas corporais se assenta mais uma vez em Baudrillard, na medida em que este Autor foi o primeiro a interpretar a "entrada" do corpo no campo das significações do consumo, circuito este modernamente impregnado pelos valores do individualismo, da competição e da personalização. Os ideais de boa forma, aparência física, "linha estética", "saúde", etc., e os comportamentos pragmáticos a eles associados, criam um ambiente cultural de valorizações positivas extremamente propício para a produção industrial, seriada, de mercadorias (bens e serviços) destinadas à sua concretização.

Mudanças culturais de grande vulto também estão na base deste processo. A crescente secularização do modo de vida, que implicou um abandono das concepções religiosas do corpo humano, novos padrões de moralidade vigente e dominantes no mundo urbano-industrial e, também, o conjunto de transformações verificadas após os anos 60 denominado genericamente como "revolução sexual", muito contribuíram para esta nova institucionalização do corpo como significante no universo de consumo e para a mercantilização das atividades corporais.

Se isto de certa forma explica e se explica pela constituição de um mercado capitalista, como analisar a outra face do fenômeno da mercantilização do esporte, que é sua transformação em espetáculo?

Como demonstra Gebara, ${ }^{6}$ o espetáculo esportivo se constitui e se desenvolve num "mercado onde o consumo se define pelo tempo socialmente disponível, preponderantemente comercializado pela mídia (...)". E, em seguida, "trata-se de aproveitar a existência tanto deste tempo como de um enorme contingente de praticantes amadores para construir um mercado voltado para grandes públicos com potencial de consumo de imagens espetaculares (...)”.

Neste contexto, dá-se a integração da construção econômica do mercado com os valores relativos à atividade corporal. $\mathrm{O}$ atleta (profissional) exerce a função de modelo, seja do ponto de vista de valores relativos ao corpo (no sentido da personalização), seja do ponto de vista da performance (no sentido da competição), ou ainda, da perspectiva da ascensão social através do uso institucionalizado do corpo.

Em suma, a expansão dos mercados de artefatos e serviços esportivos ocorre em estreita relação com a criação, destruição e recriação de modelos de saúde, de atleta vitorioso, de distinção

\footnotetext{
${ }^{6}$ Gebara, op.cit., pp. 188-9.
} 
social e pessoal, que caracterizam a ação dos principais canais da mídia e que, por sua vez, guardam uma íntima relação com a lógica de produção e comercialização de eventos esportivos.

\section{ABSTRACT}

The object of this work is the discussion of the relations between sport and consumption in the modern society. It is intended to demonstrate how relative phenomena to the consumption gain a new updating, in a historical perspective, especially for the reason of a new and vast scene of social values. Marketing, individualization and arising of models are concepts that permit to capture the new reality of the sport in the contemporary world and its transformation in merchandise.

Key words: Marketing, society of consumption, sport

\section{Referências}

BAUDRILlARD, J. La Société de Consommation: ses mythes, ses structures. Paris : Denoël, 1970.

BAUDRILLARD, J. A moral dos objetos. Função-signo e lógica de classe. In: MOLES, A. A. et al. Semiologia dos Objetos. Petrópolis : Vozes, 1972. (Novas perspectivas em comunicação; 4).

GEBARA, A. O tempo na construção do objeto de estudo da história do esporte, do lazer e da educação física. In: ENCONTRO NACIONAL DE HISTÓRIA DO ESPORTE, DO LAZER E DA EDUCAÇÃO FÍSICA, 2., 1994, Ponta Grossa. Anais... Ponta Grossa, 1994.

GIOVANNI, G. Di. A questão dos remédios no Brasil: produção e consumo. São Paulo : Polis, 1980.

GRANOU, A. Consumo y producción en el sistema capitalista. Barcelona : Cuadernos Beta, 1972. 